\title{
Quality of life after Uphold (TM) Vaginal Support System surgery for apical pelvic organ prolapse-A prospective multicenter study
}

\section{Rahkola-Soisalo, Paivi}

\section{7-01}

Rahkola-Soisalo , P, Altman, D , Falconer , C, Morcos , E, Rudnicki , M \& Mikkola , T S 2017 , ' Quality of life after Uphold (TM) Vaginal Support System surgery for apical pelvic organ prolapse-A prospective multicenter study ' , European Journal of Obstetrics, and Gynecology ,and Reproductive Biology , vol. 208 , pp. 86-90 . https://doi.org/10.1016/j.ejogrb.2016.11.011

http://hdl.handle.net/10138/233265

https://doi.org/10.1016/j.ejogrb.2016.11.011

publishedVersion

Downloaded from Helda, University of Helsinki institutional repository.

This is an electronic reprint of the original article.

This reprint may differ from the original in pagination and typographic detail.

Please cite the original version. 
Full length article

\title{
Quality of life after Uphold ${ }^{\mathrm{TM}}$ Vaginal Support System surgery for apical pelvic organ prolapse-A prospective multicenter study
}

\author{
Päivi Rahkola-Soisalo ${ }^{\mathrm{a}, *}$, Daniel Altman ${ }^{\mathrm{b}, \mathrm{c}}$, Christian Falconer $^{\mathrm{c}}$, Edward Morcos $^{\mathrm{c}}$, \\ Martin Rudnicki ${ }^{\mathrm{d}}$, Tomi S. Mikkola ${ }^{\mathrm{a}, \mathrm{e}}$ \\ a University of Helsinki and Helsinki University Central Hospital, Department of Obstetrics and Gynecology, Finland

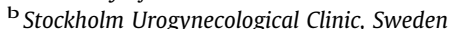 \\ ${ }^{\mathrm{c}}$ Division of Obstetrics and Gynecology, Karolinska Institutet Danderyd Hospital, Sweden \\ d Odense University Hospital, Department of Obstetrics and Gynecology, Denmark \\ e Folkhälsan Research Center, Helsinki, Finland
}

\section{A R T I C L E I N F O}

\section{Article history:}

Received 13 May 2016

Received in revised form 4 October 2016

Accepted 13 November 2016

\section{Keywords:}

Quality of life

Pelvic organ prolapse

Cystocele

Uterine prolapse

Transvaginal mesh

\begin{abstract}
A B S T R A C T
Objective: To study the effects on quality of life in women operated for apical pelvic organ prolapse using the Vaginal Uphold ${ }^{\mathrm{TM}}$ System.

Study design: In this prospective cohort study, women $(\mathrm{n}=207)$ with symptomatic apical prolapse, with or without cystocele, were operated using the Uphold ${ }^{\mathrm{TM}}$ Vaginal Support System. Follow-up for quality of life was performed at 12 months after surgery, and assessed by the PFDI-20, and PFIQ-7, and sexual function by the PISQ-12. We used odds ratios (ORs) with 95\% confidence intervals (CIs) for outcome association analyses using logistic regression.

Results: At one-year follow-up majority of women experienced an overall postoperative improvement in quality of life $(p<0.001)$. One year after surgery Uphold ${ }^{\mathrm{TM}}$ operation alone increased the risk for prolapse related bother as compared to Uphold ${ }^{\mathrm{TM}}$ combined with anterior colporraphy (POP-IQ-7; OR 2.1; 95\% CI $1.01-4.3)$. The frequency of dyspareunia decreased postoperatively $(p=0.004)$, however, after one-year, overall sexual function deteriorated significantly $(p<0.001)$. The worsening in sexual function scores was mainly attributed to the partner related domain, whereas the behavioral-emotive and physical domains showed no significant changes.

Conclusion: Apical prolapse repair using Uphold ${ }^{\mathrm{TM}}$ improved quality of life among our patients but worsened overall sexual function postoperatively.
\end{abstract}

(c) 2016 Elsevier Ireland Ltd. All rights reserved.

\section{Introduction}

Although the restoration of vaginal topography often results in improvements in pelvic organ prolapse symptoms the incongruence between objective and subjective outcomes in pelvic organ prolapse surgery is well established [1-3]. As a consequence, the focus of pelvic organ prolapse surgery has pivoted towards patients centered outcomes and quality of life measures, [4-6] rather than simply measuring pelvic anatomy outcomes of surgery.

In women after pelvic organ prolapse surgery quality of life measures may entail a variety of domains of which the effects on sexual function has received perhaps the most attention [7]. Nonetheless, it remains unclear how, and to what extent, sexual dysfunction relates to pelvic reconstructive surgery. Some studies suggest that sexual dysfunction is a common sequela after mesh augmented reconstructive surgery [8,9], others suggest that surgery has no effect [10-12], or even improve sexual function domains [13,14]. Ambiguous results have also been shown for other quality of life domains in relation pelvic organ prolapse surgery.

We have previously reported on the safety and efficacy outcomes and subjective relief of condition specific symptoms after using the Uphold ${ }^{\mathrm{TM}}$ Vaginal Support System [15]. In the present study we assessed quality of life and sexual function outcomes following Uphold ${ }^{\mathrm{TM}}$ surgery in a prospective cohort of women with apical prolapse and with or without concurrent cystocele.

\footnotetext{
* Corresponding author at: Helsinki University Hospital, Department of Obstetrics and Gynecology, BOX 140, 00029 HUS, Helsinki, Finland.

E-mail address: paivi.rahkola-soisalo@hus.fi (P. Rahkola-Soisalo).
} 


\section{Materials and methods}

We performed a multicenter, prospective, open label, single cohort study throughout 24 clinics in Sweden, Denmark, Norway and Finland. A total of 207 patients with primary or secondary apical prolapse $\geq$ stage 2 (point C/D), with or without anterior vaginal wall prolapse $>$ or equal to -1 (point $\mathrm{Ba}>-1$ ), according to POP-Q staging [16], underwent surgery using the Uphold ${ }^{\mathrm{TM}}$ Lite Vaginal Support System (Boston Scientific). All patients underwent a pre-trial standardized surgical procedure using the Uphold ${ }^{\mathrm{TM}}$ Lite system and all gynecologic surgeons participating in the trial had supervised hands-on operating room training before initiation of the study. The surgical procedure has been described elsewhere [17]. Briefly a small incision was used, leaving approximately $2 \mathrm{~cm}$ undisturbed at the vaginal apex. The Capio ${ }^{\circledR}$ Suture Capturing Device was used to connect the mesh to the sacrospinosus ligament and suspending the apex. If decided by the operator, anterior vaginal wall prolapse was corrected concomitantly by traditional colporraphia anterior, but there was not any stage of prolapse when this was mandatory. The peri- and postoperative morbidity and complications associated with the procedure were reported by Altman et al. [15]. Follow-up visits were performed at two months and one year after surgery. Five women did not attend any follow-up and thus, the final cohort was 202 women.

There were no restrictions on body mass index, menopausal status, or previous surgery. Other pelvic disorders for which surgery was indicated (including stress incontinence, cervix elongation and posterior prolapse), as well as, previous or current pelvic organ cancer, severe rheumatic disease, insulin treated diabetes mellitus, connective tissue disorder, and current systemic steroid treatment were regarded as exclusion criteria's.

Vaginal topography and quantification of pelvic organ prolapse was assessed at baseline, as well as, after two months and one year postoperatively during a gynecological exam in the lithotomy position using the POP-Q system [16]. Stage $<2$ of the apical compartment was considered an optimal anatomical outcome after surgery.

Quality of life outcomes were assessed using the Pelvic Floor Distress Inventory 20 (PFDI-20), Pelvic Floor Impact Questionnaire- short form 7 (PFIQ-7), Pelvic Organ Prolapse/Urinary Incontinence Sexual Questionnaire (PISQ-12) at baseline and one year follow-up. The main results of PFDI-20 are reported before [15], but these data were included here when analyzing the possible risk factors for subjective operation failure. The PFIQ-7 provides a comprehensive condition specific assessment of the effect of pelvic floor distress on quality of life during the last three months. The questionnaire includes seven questions and three scales: Urinary Impact Questionnaire (UIQ-7), Colorectal-Anal Impact Questionnaire (CRAIQ-7), and Pelvic Organ Prolapse Impact Questionnaire (POPIQ-7). The scale score is obtained by the mean value of all the answered questions and multiplying them to obtain scale score from 0 (least impact) to 100 (greatest impact). In the summary higher points indicates more distress. The PISQ consists of 12 questions, which measures the impact of pelvic organ prolapse on the patient's sexual life during the last six months. The responses are graded on a 5-point Likert scale from "never" to "always". The questionnaire can be divided to three subscales, behavior-emotional, physical, and partner related. Higher points indicate better sexual satisfaction and the maximum score is 48 .

Data on the quality of life questionnaires are presented as means \pm SD. Comparison between baseline and one-year outcomes were analyzed by the Wilcoxon -Matched-Paired-SignedRank test. As possible risk factors for unsuccessful outcomes (i.e. POP-Q stage $\geq 2$ in point $C$ or an adverse effects on quality of life instruments) we evaluated a number of variables in a multivariate logistic regression analysis including: previous hysterectomy, previous pelvic organ prolapse surgery, age $>65$ years, BMI $\geq 25$, multiparity ( $\geq 3$ deliveries), chronic diseases (cardiovascular diseases, asthma, thyroidea dysfunction, non-insulin treated diabetes, fibromyalgia, rheumatism), and concomitant anterior vaginal wall repair. Results from the risk analysis are presented as odds ratios (ORs) with 95\% confidence intervals (CIs). A $p$-value $<0.05$ was considered significant for all analyses. All statistics were performed with IBM SPSS Statistics, version 22.

The study was approved by the appropriate research ethics committees in the participating countries and the study was registered at www.clinicaltrials.gov (NCT01823055). The study protocol was vetted by the mesh manufacturing company prior to providing an investigator initiated study grant but the company had no further influence over execution of the study, analyses and interpretation of the data, or drafting the manuscript. Furthermore, the company provided funding for two investigator meetings held before and after completion of the trial.

\section{Results}

Baseline characteristics of the patients included in the study are presented in Table 1 . In total $88 \%$ of the women were postmenopausal (183) and 38\% (79 women) had a history of previous hysterectomy. Mean age at surgery was $66.3(S D \pm 9.2)$ years, mean body mass index (BMI) was $25.3(\mathrm{SD} \pm 4.6)$ and median parity was 2 (range 0-5).

The PFIQ-7 questionnaire was filled adequately by 197 women at baseline, and after one year by 183 women. Of these women 179 filled the questionnaires adequately both at baseline and at one year. One hundred-sixteen (64.8\%) women had lower score points one year postoperatively indicating an improved quality of life, 19 (10.6\%) women reported no change, and 44 (24.6\%) women showed worsening in quality of life. Detailed outcome of PFIQ-7 questionnaire is presented in Table 2. Pelvic organ prolapse and urinary symptoms caused equal distress before the operation. The total score points showed an overall improved quality of life at oneyear follow-up $(p<0.001)$ (Table 2$)$. Both pelvic organ prolapse and urinary problems improved significantly after one year $(p<0.001)$, whereas in the colorectal-anal scale no statistically significant change was detected (Table 2).

Table 1

Baseline characteristics and the operation information.

\begin{tabular}{ll}
\hline Age y, mean \pm SD (range) & $66.3 \pm 9.2(34-92)$ \\
Weight & $70.1 \pm 9.4$ \\
BMI mean \pm SD (range) & $25.3 \pm 4.6(19.6-$ \\
& $35.3)$ \\
Parity median (range) & $2(0-5)$ \\
Multiparous ( $\geq 3$ deliveries) N (\%) & $78(38)$ \\
Menopause N (\%) & $183(88)$ \\
Smokers N (\%) & $11(5)$ \\
& \\
Somatic diseases N (\%) & \\
No diseases & $68(33)$ \\
Cardiovascular diseases & $81(39)$ \\
Thyroid dysfunction & $21(10)$ \\
Asthma & $12(6)$ \\
Diabetes & $4(2)$ \\
Fibromyalgia + rheumatism & $6(3)$ \\
Other & $4(2)$ \\
& \\
Previous surgeries N (\%) & \\
Hysterectomy & $79(38)$ \\
Subjects with previous pelvic floor surgery & $88(43)$ \\
Hysterectomy or incontinence + colporraphia anterior & $39(19)$ \\
Operating time min (mean \pm SD) & $54.6 \pm 18.8$ \\
Bleeding ml, mean \pm SD (range) & $78 \pm 122(0-1000)$ \\
Hospital stay days median (range) & $2(0-7)$ \\
\hline
\end{tabular}


Table 2

Pelvic floor impact quality questionnaire results.

\begin{tabular}{lccl}
\hline & Preop. $\mathrm{N}=197$ & 1 year $\mathrm{N}=183$ & $p$ \\
\hline Pelvic organ prolapse impact & $49.4 \pm 25$ & $36.4 \pm 13.1$ & $<0.001$ \\
Colorectal-anal impact & $39.1 \pm 20.4$ & $36.2 \pm 11.7$ & 0.3 \\
Urinary impact & $49.7 \pm 23.3$ & $40.1 \pm 13.1$ & $<0.001$ \\
Total & $138.5 \pm 59.8$ & $105.1 \pm 42.5$ & $<0.001$ \\
\hline
\end{tabular}

Means \pm SD.

At baseline 95 women and after one year 97 women answered the PISQ-12 questionnaire adequately. Of these 94 women answered completely for both questionnaires. In $62(66.0 \%)$ women total score points reduced postoperatively indicating worsening in sexual function, 10 (10.6\%) women reported unchanged situation, and 22 (23.4\%) women showed improved sexual function. Overall sexual satisfaction was reduced $(p<0.001)$ after one-year follow-up (Table 3 ). In the subscale analyses the score points did not differ in the behavioral-emotive and physical sections before and after surgery. There was, however, a specific decrease in the partner related subscale postoperatively (Table 3 ).

With regard to postoperative dyspareunia in specific (PISQ-12, question 5) a total of 98 women answered the question both pre and postoperatively. Of these 58/98 women (59.2\%) had some dyspareunia preoperatively whereas 42 reported $(42.9 \%)$ dyspareunia postoperatively $(p=0.004)$. Fifty patients reported no change, 32 patients improved, and in 16 patients dyspareunia worsened. A worsening in dyspareunia was reported by $8.1 \%$ of all studied women having an Uphold procedure vs. 8.3\% among women having Uphold with concomitant colporraphy $(p=0.9)$. Similarly, $12.5 \%$ of women reported a complete resolution of dyspareunia after an isolated Uphold procedure vs. $11.7 \%$ among patients having Uphold with concomitant colporraphy $(p=0.6)$.

In Table 4 we present the results for the association between possible predictors and a worsening of condition specific symptoms, quality of life, sexual function and anatomical outcomes. Chronic disease improved the odds of quality of life improvement (OR 0.4, 95\% CI; 0.2-0.9) whereas an age $\geq 65$ increased the risk for de novo pelvic organ prolapse (OR 2.5, 95\% CI; 1.01-6.2). There were no significant associations between any of

Table 3

Pelvic Organ prolapse/Urinary Incontinence Sexual Questionnaire results.

\begin{tabular}{lccl}
\hline & Baseline $\mathrm{N}=95$ & 1 year $\mathrm{N}=97$ & $p$ \\
\hline Behavioral emotive & $6.9 \pm 3.5$ & $6.8 \pm 3.3$ & 0.7 \\
Physical & $4.7 \pm 3.0$ & $4.2 \pm 2.6$ & 0.07 \\
Partner & $3.6 \pm 2.9$ & $1.6 \pm 2.5$ & $<0.001$ \\
Summary Score & $15.2 \pm 6.1$ & $12.6 \pm 6.2$ & $<0.001$ \\
\hline
\end{tabular}

Means \pm SD. the co-variates and sexual dysfunction or anatomical outcomes (Table 4).

In the subscale analyses of both the PFDI-20 (UDI-6) and the PIFQ-7 (UIQ-7) there was increased odds for improved urinary distress in women with BMI $\geq 25$ (OR 0.3, 95\% CI; 0.1-0.7, and OR $0.5,95 \% \mathrm{CI} ; 0.2-0.9$, respectively). Among women with a history of previous pelvic floor surgery and among women with an isolated Uphold $^{\mathrm{TM}}$ (no concurrent anterior colporraphy) there was an increased risk that the operation worsened urinary distress (UIQ-7; OR 2.2, 95\% CI; 1.1-4.4 and OR 2.3, 95\% CI; 1.1-4.9, respectively). Having an isolated Uphold ${ }^{\mathrm{TM}}$ operation also increased the risk for prolapse related bother one year after surgery (POP-IQ-7; OR 2.1, 95\% CI; 1.01-4.3).

\section{Comment}

The total scores indicated that the Uphold $^{\mathrm{TM}}$ operation significantly improved quality of life as reflected by lower scores postoperatively for the PFIQ-7. At baseline there was almost as much distress from urinary symptoms as from pelvic organ prolapse, and both these symptoms of pelvic floor dysfunction improved significantly after the operation. These results are comparable with previous studies on the use of mesh in pelvic organ prolapse repair [3,14,18-20].

Despite the improvement in quality of life, PISQ-12 scores showed an overall worsening in sexual function 1-year postoperatively. The deterioration was mainly attributed to negative effects in the partner related domain whereas the behavioral-emotive and physical domains showed no significant changes. To some extent this concurs with a previous cohort study showing that transvaginal mesh is associated with deteriorating partner related sexual function [8]. Although partner related sexual dysfunction after prolapse surgery is a recurrent finding in studies on pelvic organ prolapse surgery the mechanisms for this finding are poorly understood. It is possible that the PISQ-questionnaire as a tool to describe sexual function, although responsive to change after surgery [21], does not provide a comprehensive and detailed enough evaluation of the complexity involved in sexual function after reconstructive surgery. In-depth studies on sexual dysfunction related to pelvic organ prolapse surgery are scarce. In a mixed quantitative and qualitative study [22], the investigators found that partner avoidance of sexual activity was greater in women after prolapse surgery as compared to incontinence surgery. In contrast, another study [23] showed that sexual function in male partners of women after pelvic organ prolapse surgery was unchanged or even improved. Moreover, it is possible that this worsening is attributable to prolapse surgery itself - regardless of using mesh or not [24]. However, we may conclude that partner related dysfunction after mesh augmented or native tissue prolapse repair may be an important cause of postoperative sexual dysfunction and deserves further attention.

Table 4

Odd ratios OR for unsuccessful operation result after one year follow-up (POP-Q $<2$ apical compartment, PFDI-20, PFIQ-7, PISQ-12).

\begin{tabular}{|c|c|c|c|c|c|c|c|c|c|c|}
\hline & \multicolumn{2}{|c|}{ De novo prolapse } & \multicolumn{2}{|c|}{ Apical success } & \multicolumn{2}{|c|}{ PFDI-20 } & \multicolumn{2}{|c|}{ PFIQ-7 } & \multicolumn{2}{|c|}{ PISQ-12 } \\
\hline & OR & $95 \% \mathrm{CI}$ & OR & $95 \% \mathrm{CI}$ & OR & $95 \% \mathrm{CI}$ & OR & $95 \% \mathrm{CI}$ & OR & $95 \% \mathrm{CI}$ \\
\hline Previous hysterectomy & 1.2 & $0.5-2.7$ & 0.8 & $0.2-3.3$ & 0.8 & $0.2-3.0$ & 0.5 & $0.2-1.1$ & 1.1 & $0.4-3.1$ \\
\hline Previous pelvic floor surgery & 0.8 & $0.4-1.7$ & 1.1 & $0.3-4.6$ & 2.4 & $0.8-7.1$ & 1.0 & $0.5-2.3$ & 1.0 & $0.4-2.8$ \\
\hline $\mathrm{BMI} \geq 25$ & 1.3 & $0.6-2.8$ & 0.8 & $0.2-3.6$ & 0.5 & $0.1-1.6$ & 0.8 & $0.4-1.6$ & 0.7 & $0.3-1.9$ \\
\hline Multiparous & 1.1 & $0.5-2.4$ & 0.6 & $0.2-3.3$ & 0.7 & $0.2-2.5$ & 2.1 & $1.0-4.2$ & 1.4 & $0.5-3.8$ \\
\hline Age $\geq 65$ & $\begin{array}{l}2.5 \\
0.047^{*}\end{array}$ & $1.01-6.2$ & 0.2 & $0.2-1.9$ & 3.6 & $0.7-18.1$ & 1.1 & $0.5-2.4$ & 0.9 & $0.3-2.5$ \\
\hline Chronic disease & 0.8 & $0.4-1.9$ & 0.7 & $0.1-4.0$ & 3.3 & $0.7-16.3$ & $\begin{array}{l}0.4 \\
0.02^{*}\end{array}$ & $0.2-0.9$ & 0.8 & $0.3-2.3$ \\
\hline Isolated Uphold ${ }^{\mathrm{TM}}$ operation & 0.5 & $0.2-1.1$ & 0.5 & $0.1-2.0$ & 1.5 & $0.4-5.1$ & 1.5 & $0.7-3.1$ & 1.0 & $0.3-2.9$ \\
\hline
\end{tabular}

$p$-values for significant OR. 
Postoperative dyspareunia is the area of sexual dysfunction that has received the greatest attention relating to urogynecological surgery. Again findings from previous studies are conflicting and some studies show an increased risk for dyspareunia after surgery whereas others detected no change [8-14]. We found that the number of women with dyspareunia decreased postoperatively, even if almost half of the women who answered the question (42/ 98 ) had some dyspareunia one year after the operation. Most of these women presented dyspareunia seldom or sometimes, and only four women had pain often or always. However, it is notable that only $48.5 \%$ of women answered the question and thus, it is possible that the true rate of dyspareunia was higher. There was no difference in either worsening or improvement of dyspareunia when comparing women having an isolated Uphold ${ }^{\mathrm{TM}}$ procedure compared to those having it in combination with anterior colporraphy. These numbers are comparable with previous study where $8 \%$ of women had de novo dyspareunia after Uphold operation [25]. It is possible that the decreased biomaterial load and smaller surface of the mesh when performing an apical suspension procedure such as Uphold ${ }^{\mathrm{TM}}$ decreases the risk for postoperative dyspareunia when compared to the large scale transvaginal meshes used to cover defects of the vaginal walls $[8,9]$. Thus, our data suggest that performing an anterior colporraphy at the time of an Uphold procedure does not add to the risk of postoperative dyspareunia, whereas overall conclusions on sexual function and dyspareunia are restricted.

We evaluated risk factors in subjective and objective outcomes, as well as, for de novo prolapse. Surprisingly, the only significant variable positively associated with an overall improvement in quality of life (PFIQ-7) was co-existent chronic diseases. It is possible that women afflicted by multiple chronic diseases experience after surgery improvements in prolapse symptoms more clearly than otherwise healthy women with perhaps greater expectations on daily function. Age $\geq 65$ years was a risk factor for de novo prolapse which likely reflects the association between prolapse and age [26]. In addition, it is possible that among elderly women, with overall poorer tissue quality, the effectiveness of mesh surgery in the afflicted compartment may promote de novo prolapse in other compartments [27].

Women having an isolated Uphold ${ }^{\mathrm{TM}}$ operation reported less improvement in both lower urinary tract and pelvic organ prolapse related distress as compared to women having a concomitant cystocele operation. This is in line with our finding that women without any preoperative cystocele reported at baseline less urinary distress (PFDI-20; $\mathrm{p}=0.004$ ). Concomitant cystocele repair may increase the support of the bladder neck providing additional improvement of lower urinary tract symptoms and especially stress urinary incontinence. It is known that isolated traditional cystocele correction relives preoperative stress urinary incontinence in $27 \%$ of the women [28]. Furthermore, the concomitant cystocele repair probably provide better overall support to the anterior compartment than Uphold ${ }^{\mathrm{TM}}$ alone resulting in improved symptom relief. In the subscale analyses of both the PFDI-20 and PFIQ-7, a higher degree of satisfaction with regard to lower urinary tract symptoms were found in obese women (BMI $\geq 25$ ). Since obese women had more distress in the urinary sections preoperatively (PFDI-20; $\mathrm{p}<0.001$, PFIQ-7; $\mathrm{p}=0.06$ ), they likely benefited more from the operation than normal weight women.

The apparent limitation of our study is that approximately half of our patients chose not to reply to the PISQ-12. In addition, our non-randomized study design include potential bias such as doctor-patient relationship, care seeking behavior, and patient/ surgeon preferences. As a strength of our study can be regarded the prospective, multicenter and multinational study setting.

In conclusion, use of the Vaginal Uphold ${ }^{\mathrm{TM}}$ Support System for apical prolapse repair improve quality of life and no specific risk factors for subjective operation failure could be identified. However, there was an overall worsening in sexual function postoperatively.

\section{Conflict of interest}

E. Marcos report no conflict of interest, P. Rahkola-Soisalo has received advisory honoraria from Johnson \& Johnson, M. Rudnicki has received advisory honoraria from Pfizer, D Altman has received speaking and advisory honoraria from Gedeon Richter, Pfizer, Astellas, Invent Medic and Gynecare. C. Falconer has received speaking and advisory honoraria from Boston Scientific and Johnson \& Johnson. T. S. Mikkola has received speaking honoraria from Astellas and Contura.

\section{Acknowledgements}

The study was supported by an investigator initiated grant from Boston Scientific, grants from the Finnish Medical Foundation, and the Swedish Scientific Council.

\section{References}

[1] Nguyen JN, Burchette RJ. Outcome after anterior vaginal prolapse repair: a randomized controlled trial. Obstet Gynecol 2008;111:891-8.

[2] Altman D, Vayrynen T, Engh ME, Axelsen S, Falconer C, Nordic Transvaginal Mesh Group. Anterior colporrhaphy versus transvaginal mesh for pelvic-organ prolapse. N Engl J Med 2011;364:1826-36.

[3] Lamblin G, Van-Nieuwenhuyse A, Chabert P, Lebail-Carval K, Moret S, Mellier G. A randomized controlled trial comparing anatomical and functional outcome between vaginal colposuspension and transvaginal mesh. Int Urogynecol J 2014;25:961-70.

[4] Hullfish KL, Bovbjerg VE, Gibson J, Steers WD. Patient-centered goals for pelvic floor dysfunction surgery: what is success, and is it achieved? Am J Obstet Gynecol 2002;187:88-92.

[5] Brubaker L. Controversies and uncertainties: abdominal versus vaginal surgery for pelvic organ prolapse. Am J Obstet Gynecol 2005;192:690-3.

[6] Bovbjerg VE, Trowbridge ER, Barber MD, Martirosian TE, Steers WD, Hullfish KL. Patient-centered treatment goals for pelvic floor disorders: association with quality-of-life and patient satisfaction. Am J Obstet Gynecol 2009;200:568 e1-e6.

[7] Glavind K, Larsen T, Lindquist AS. Sexual function in women before and after tension-free vaginal tape operation for stress urinary incontinence. Acta Obstet Gynecol Scand 2014;93:986-90.

[8] Altman D, Elmer C, Kiilholma P, Kinne I, Tegerstedt G, Falconer C, et al. Sexual dysfunction after trocar-guided transvaginal mesh repair of pelvic organ prolapse. Obstet Gynecol 2009;113:127-33.

9] Liang CC, Lo TS, Tseng LH, Lin YH, Lin YJ, Chang SD. Sexual function in women following transvaginal mesh procedures for the treatment of pelvic organ prolapse. Int Urogynecol J 2012;23:1455-60.

[10] Milani AL, Withagen MI, The HS, Nedelcu-van der Wijk I, Vierhout ME. Sexual function following trocar-guided mesh or vaginal native tissue repair in recurrent prolapse: a randomized controlled trial. J Sex Med 2011;8:2944-53.

[11] Bartuzi A, Futyma K, Kulik-Rechberger B, Skorupski P, Rechberger T. Transvaginal Prolift ${ }^{\mathbb{B}}$ mesh surgery due to advanced pelvic organ prolapse does not impair female sexual function: a prospective study. Eur J Obstet Gynecol Reprod Biol 2012;165:295-8.

[12] Alperin M, Ellison R, Meyn L, Frankman E, Zyczynski HM. Two-year outcomes after vaginal prolapse reconstruction with mesh pelvic floor repair system. Female Pelvic Med Reconstr Surg 2013;19:72-8.

[13] Nieminen K, Hiltunen R, Heiskanen E, Takala T, Niemi K, Merikari M, et al. Symptom resolution and sexual function after anterior vaginal wall repair with or without polypropylene mesh. Int Urogynecol J Pelvic Floor Dysfunct 2008;19:1611-6.

[14] El Haddad R, Svabik K, Masata J, Koleska T, Hubka P, Martan A. Women's quality of life and sexual function after transvaginal anterior repair with mesh insertion. Eur J Obstet Gynecol Reprod Biol 2013;167:110-3.

[15] Altman D, Mikkola TS, Möller Bek K, Rahkola-Soisalo P, Gunnarsson J, Ellström Engh M, et al. Pelvic organ prolapse repair using the Uphold ${ }^{\mathrm{TM}}$ vaginal support system - a 1-year multicenter study. Int Urogynecol J 2016;27:1337-45.

[16] Bump RC, Mattiasson A, Bo K, Brubaker LP, DeLancey JO, Klarskov P, et al. The standardization of terminology of female pelvic organ prolapse and pelvic floor dysfunction. Am J Obstet Gynecol 1996:175:10-7.

[17] Vu MK, Letko J, Jirschele K, Gafni-Kane A, Nguyen A, Du H, et al. Minimal mesh repair for apical and anterior prolapse: initial anatomical and subjective outcomes. Int Urogynecol J 2012;23:1753-61.

[18] Elmer C, Altman D, Engh ME, Axelsen S, Vayrynen T, Falconer C, et al. Trocarguided transvaginal mesh repair of pelvic organ prolapse. Obstet Gynecol 2009;113:117-26. 
[19] Nieminen K, Hiltunen R, Takala T, Heiskanen E, Merikari M, Niemi K, et al. Outcomes after anterior vaginal wall repair with mesh: a randomized, controlled trial with a 3 year follow-up. Am J Obstet Gynecol 2010;203:235 e1-e8.

[20] Withagen MI, Milani AL, den Boon J, Vervest HA, Vierhout ME. Trocar-guided mesh compared with conventional vaginal repair in recurrent prolapse: a randomized controlled trial. Obstet Gynecol 2011;117:242-50.

[21] Rogers RG, Kammerer-Doak D, Villarreal A, Coates K, Qualls C. A new instrument to measure sexual function in women with urinary incontinence or pelvic organ prolapse. Am J Obstet Gynecol 2001;184:552-8.

[22] Roos AM, Thakar R, Sultan AH, de Leeuw JW, Paulus AT. The impact of pelvic floor surgery on female sexual function: a mixed quantitative and qualitative study. BJOG 2014;121:92-100.

[23] Lonnee-Hoffmann RA, Salvesen O, Morkved S, Schei B. Male sexual function and pelvic floor surgery of their female partner: a one-year follow-up study. Post Reprod Health 2014;20:55-61.
[24] Dietz V, Maher C. Pelvic organ prolapse and sexual function. Int Urogynecol J 2013;24:1853-7.

[25] Letouzey V, Ulrich D, Balenbois E, Cornille A, de Tayrac R, Fatton B. Uterovaginal suspension using bilateral vaginal anterior sacrospinous fixation with mesh: intermediate results of a cohort study. Int Urogynecol J 2015;26:1803-7.

[26] Barber MD, Maher C. Epidemiology and outcome assessment of pelvic organ prolapse. Int Urogynecol J 2013;24:1783-90.

[27] Maher C, Feiner B, Baessler K, Schmid C. Surgical management of pelvic organ prolapse in women. Cochrane Database Syst Rev 2013;4:CD004014.

[28] Borstad E, Abdelnoor M, Staff AC, Kulseng-Hanssen S. Surgical strategies for women with pelvic organ prolapse and urinary stress incontinence. Int Urogynecol J 2010;21:179-86. 